Disponível em:

http://editora.unoesc.edu.br/index.php/race

Race, Joaçaba, v. 14, n. 2, p. 769-796, maio/ago. 2015

\title{
QUALIDADE INFORMACIONAL E NÍVEL DE TRANSPARÊNCIA: UM ESTUDO ENTRE EMPRESAS GANHADORAS E NÃO GANHADORAS DO TROFÉU TRANSPARÊNCIA FIPECAFI-SERASA EXPERIAN
}

\section{Informational quality and transparency level: a study between companies a winning nd non-winning transparency fipecafi-serasa experian trophy}

\begin{abstract}
Vagner Antonio Marques
E-mail: vmarques@pucminas.br Mestre em Ciências Contábeis pela Universidade Federal de Minas Gerais; doutorando em Administração (Finanças) pela Universidade Federal de Minas Gerais;

Professor Assistente da Pontifícia Universidade Católica de Minas Gerais.
\end{abstract}

Fabrine Gonçalves Dias da Silva

E-mail: fabrinedias@hotmail.com

Graduada em Ciências Contábeis pela Pontifícia Universidade Católica de Minas Gerais; pós-graduanda em Controladoria Financeira pela Pontifícia Universidade Católica de Minas Gerais.

\section{Luiz Cláudio Louzada}

E-mail: louzadalvi@yahoo.com.br

Mestre em Ciências Contábeis pela Fundação Instituto Capixaba de Pesquisas em Contabilidade, Economia e Finanças; doutorando em Administração (Finanças) pela Universidade Federal de Minas Gerais; Professor Assistente do Departamento de Ciências Contábeis da Universidade Federal do Espírito Santo.

Hudson Fernandes Amaral E-mail: hfamaral@face.ufmg.br

Doutor em Sciences de Gestion pela Université Pierre Mendès France, ESA, Grenoble II, França; Mestre em Diplôme dEtudes Approfondies en Sciences de Gestion, Université Des Sciences Sociales de Toulouse I, França; Professor Titular da Universidade Federal de Minas Gerais. Endereço para contato: Avenida Presidente Antônio Carlos, 6627, Pampulha, 31270-901, Belo Horizonte, Minas Gerais, Brasil.

Antônio Artur de Souza

E-mail: artur@face.ufmg.br

Doutor em Management Science pela The University of Lancaster; Mestre em Engenharia de Produção pela Universidade Federal de Santa Catarina; Professor Adjunto da Universidade Federal de Minas Gerais. 


\title{
Resumo
}

A literatura estrangeira tem recorrentemente apresentado evidências de que a estrutura de governança e o nível de transparência afetam a qualidade informacional dos números contábeis. Diante disso, o objetivo do presente estudo foi analisar a relação entre a qualidade das informações contábeis e o nível de transparência das empresas brasileiras. O estudo é descritivo, documental e quantitativo, com dados trimestrais de 18 empresas no período de 2007 a 2013. Os resultados evidenciaram que as empresas ganhadoras do Prêmio Associação Nacional dos Executivos de Finanças, Administração e Contabilidade (ANEFAC), as correlações (entre 52,8\% e 63,1\%) entre VMA, LPA e Patrimônio Líquido por Ação (PLA) foram estatisticamente significativas. $\mathrm{O}$ modelo de regressão foi estatisticamente significativo $\left(\alpha, \beta_{1}, \beta_{2} 1\right)$ para as empresas ganhadoras, com um $R^{2} R^{2}$ de $46,78 \%$, enquanto o modelo para as não ganhadoras teve um $R^{2} R^{2}$ de $0,01 \%$. Além disso, as variáveis explicativas (LPA, PLA e intercepto) foram significativas ao nível de $1 \%$, enquanto no modelo composto por empresas não ganhadoras, o PLA não foi significativo. A maior capacidade informacional dos números contábeis das empresas ganhadoras é coerente com a teoria da divulgação.

Palavras-chave: Qualidade das informações contábeis. Relevância do valor. Nível de transparência.

\section{Informational quality and transparency level: a study between companies a winning nd non- winning transparency fipecafi-serasa experian trophy}

\begin{abstract}
The foreign literature has repeatedly showed evidences that the governance structure and the level of transparency affect the information quality of accounting numbers. Thus, the aim of this study was to analyze the relationship between the quality of financial reporting and the level of transparency of the Brazilian companies. The study is descriptive, documentary and quantity, with quarterly data from 18 companies from 2007 to 2013. The results showed that the winning companies Award National Association of Executives in Finance, Administration and Accounting (ANEFAC), correlations (between $52,8 \%$ and $63.1 \%$ ) between VMA, LPA and Shareholders' Equity per Share (PLA) were statistically significant. The regression model was statistically significant $(\alpha, 1)$ to the winning companies, with a $46.78 \%$, while for the model was not a winning 0.01\%. In addition, the explanatory variables (LPA, PLA and intercept) were significant at 1\%, while the model composed of not winning companies, the PLA was not significant. Most informational ability of accounting numbers of the winning companies is consistent with the theory of disclosure.
\end{abstract}

Keywords: Quality of accounting information. Value Relevance. Transparency level. 


\section{INTRODUÇÃO}

As demonstrações contábeis consistem em uma das principais fontes de informação financeira para a tomada de decisões, sendo um insumo relevante no processo de tomada de decisão dos usuários externos (O’GLOVE; SOBEL, 1987). Entretanto, para que essas informações cumpram o seu papel é necessário que elas alterem o estado de conhecimento do tomador de decisões sobre as entidades, influenciando, dessa forma, para o processo decisorial, na melhor tomada de decisão (DECHOW; SCHRAND, 2004).

À estrutura conceitual da contabilidade presume-se que as informações contábeis possuam características qualitativas: fundamentais (relevância e fidedignidade), consideradas indispensáveis e essenciais; e de melhoria (comparabilidade, verificabilidade, tempestividade e compreensibilidade), tidas como menos críticas, mas não menos importantes (MACKENZIE et al., 2013). A despeito dos questionamentos sobre a observância empírica dessas características (YAMAMOTO; SALOTTI, 2006), não se pode verificá-las diretamente, pois se tratam de constructos operacionalizados apenas por meio de proxies (ECKER et al., 2013).

De acordo com Dechow e Schrand (2010), uma informação financeira será considerada relevante quando possibilitar que seus usuários estimem apropriadamente o valor futuro da companhia. Ecker et al. (2013) argumentam que a qualidade das informações contábeis, estimada normalmente a partir do lucro (e suas variações, como retorno, caixa, etc.), será determinada por fatores inatos e outros fatores ligados aos relatórios divulgados. Como fatores inatos destacamse modelo de negócio e risco da operação e o ambiente operacional. Já os fatores relacionados aos relatórios citam: decisões gerenciais, sistema de informações, auditoria, estrutura de governança e ambiente regulatório (regulação e padrões contábeis). O que se verifica é que segundo a perspectiva desses autores, a qualidade é uma função de fatores ligados ao risco (operacional), o ambiente de negócios (sistema de informações) e fatores ligados à transparência (auditoria, estrutura de governança, regulação e normas de contabilidade).

A questão da transparência informacional no contexto das pesquisas na área de Contabilidade e Finanças, a partir dos trabalhos de Berle e Means (1932) e Coase (1937), e a relação entre os agentes econômicos e os contratos firmados com a firma têm sido objeto de questionamentos (JENSEN; MECKLING, 1976). Isso porque, com a separação entre a propriedade, as questões relacionadas aos problemas e aos custos de agência têm intrigado os pesquisadores dessas áreas. 
Nesse debate, a contabilidade assume papel relevante. Sunder (2014) observa que a contabilidade consiste em um sistema que facilita o adequado relacionamento entre as partes interessadas, pois demonstra a relevância do processo de prestação de contas, serve como termômetro para a avaliação de desempenho e reduz a assimetria informacional (entre agente-principal).

Na perspectiva da hipótese de eficiência de mercado, essas anomalias geram a possibilidade de obtenção de retornos anormais por determinados agentes, o que reduz a qualidade das informações contábeis (WATTS; ZIMMERMAN, 1986) e, por sua vez, prejudica os diversos usuários a utilizarem a informação contábil para decidirem sobre a alocação de seus recursos (BEAVER, 1998).

Nesse sentido, a transparência constitui-se de um elemento que minimiza o risco de que tais anomalias ocorram, fortalecendo a qualidade da informação contábil. No contexto internacional, desde a ocorrência dos casos de 2000 (Enron, Worldcom, AOL, e.g.), os reguladores têm buscado mecanismos para reduzir falhas contratuais que permitam a existência de tais eventos (RONEN, 2014). Chang, Tang e Krivogorsky (2011) observam que um desses esforços consistiu na promulgação da SarbanesOxley (SOX) em 2002, que estabeleceu regras de controle interno e transparência para companhias que negociam no mercado de capitais americano (NYSE). No contexto nacional não foi diferente. Primeiro porque as empresas nacionais que negociam na NYSE estão sujeitas às regras da SOX (OLIVEIRA; LINHARES, 2007), segundo porque instituições públicas Comissão de Valores Mobiliários (CVM) e privadas BM\&FBovespa e Instituto Brasileiro de Governança Corporativa (IBGC) têm envidado esforços no sentido de fortalecerem os mecanismos de governança das empresas brasileiras (SAITO; SILVEIRA, 2008).

Diante desse contexto, o presente estudo buscou analisar a relação entre o nível de transparência da empresa e a qualidade das informações contábeis das empresas brasileiras. Para tanto, buscou responder à seguinte pergunta: As empresas com maiores níveis de transparência apresentam maior qualidade das informações contábeis?

Para responder a essa questão foram estudadas as relações entre as variáveis apresentadas por uma amostra de 18 empresas, trimestralmente, no período de 2007 a 2013, sendo nove ganhadoras do Troféu Transparência Fipecafi-Serasa Experian e outras nove empresas que não ganharam.

Espera-se, com esta pesquisa, contribuir para o aperfeiçoamento da relação entre a Contabilidade e o Mercado de Capitais: a primeira como redutora do risco para o segundo e o segundo como laboratório para a primeira testar e validar (ou não) suas premissas, práticas e informações. Objetivamente, o trabalho pretendeu contribuir 
com evidências sobre o efeito da transparência na qualidade das informações contábeis (VERRECCHIA, 1990), sobretudo após a adoção das normas internacionais de contabilidade (Internacional Financial Reporting Standards (IFRS)). Para Ball (2006), a adoção das IFRSs teve como finalidade a melhoria da qualidade informacional dos números contábeis, logo, pode-se esperar que tal padrão pode aumentar a relação entre o valor de mercado da companhia e os números contábeis publicados por ela.

As próximas seções deste trabalho tratam, especificadamente: referencial teórico, abordando a hipótese de eficiência de mercado e a relevância da informação contábil, a governança corporativa, a transparência e a qualidade das informações e pesquisas anteriores; classificação da pesquisa; procedimentos metodológicos; análise dos dados; e considerações finais.

\section{REFERENCIAL TEÓRICO}

\section{1 HIPÓTESE DE EFICIÊNCIA DE MERCADO E A RELEVÂNCIA DA INFORMAÇÃO CONTÁBIL}

A Hipótese de Mercado Eficiente (HME) proposta pelo Nobel de Economia Eugene Fama em 1970 afetou sobremaneira as pesquisas em contabilidade (SANTOS; DIAS; DANTAS, 2014). Na perspectiva de Watts e Zimmerman (1986), a HME e o Capital Assets Pricing Model (CAPM) constituíram as pedras angulares para as pesquisas contemporâneas em Contabilidade. A HME considera que um mercado será eficiente quando os preços dos ativos representarem todo o conjunto

de informações disponíveis em determinada data $\left(\theta_{t} \theta_{t}\right)$. Na prática, isso significa que à medida que novas informações são disponibilizadas ao mercado, os preços dos títulos se ajustam (BEAVER, 1998). A HME considera que todo o mercado é eficiente, entretanto, serão classificados como eficientes em suas formas: fraca, semiforte e forte (FAMA, 1970). Em sua forma fraca, o preço dos títulos é formado a partir de informações públicas passadas sobre estes. Em sua forma semiforte, os preços dos títulos incluem as informações históricas e as atuais, disponíveis aos agentes econômicos. Por fim, em sua forma forte, os preços dos títulos incorporam inclusive as informações privadas dos agentes econômicos (insiders). Fama (1991) destaca que os testes de empíricos de eficiência podem ser por meio da preditividade 
dos retornos (return predictability), dos estudos de eventos (event studies) e dos testes para informações privadas (tests for private information).

O CAPM constituiu uma das ideias capitais em finanças (BERNSTEIN, 2008) e para a contabilidade influenciou notadamente as pesquisas que avaliavam a relevância da informação contábil para o mercado (WATTS; ZIMMERMAN, 1986). Trata-se de um modelo de equilíbrio utilizado, via de regra, para a estimativa dos retornos dos títulos. Sharpe (1964) afirma que o modelo assume as seguintes premissas: os Fluxos de Caixa Futuro são perfeitamente estimáveis, os mercados de capitais são perfeitos e os Investidores são racionais e buscam maximizar seus retornos.

Isso posto, propôs o seguinte modelo matemático:

$$
E\left(R_{i}\right)=E\left(R_{f}+\beta_{i m}\left[E\left(R_{m}\right)-R_{f}\right]\right.
$$

Onde:

$E\left(R_{i}\right) E\left(R_{i}\right)$ é o retorno esperado do ativo;

$\mathrm{R}_{\mathrm{f}} \mathrm{R}_{\mathrm{f}}$ é a taxa de juros livre de riscos;

$\beta_{\text {im }} \beta_{\text {im }}$ é o coeficiente beta, que representa a sensibilidade dos retornos do ativo em relação aos do mercado, ou ainda $\beta_{\mathrm{im}}=\frac{\operatorname{Cov}\left(\mathrm{R}_{\mathrm{i}}, \mathrm{R}_{\mathrm{m}}\right)}{\operatorname{Var}\left(\mathrm{R}_{\mathrm{m}}\right)} \beta_{\mathrm{im}}=\frac{\operatorname{Cov}\left(\mathrm{R}_{\mathrm{i}}, \mathrm{R}_{\mathrm{m}}\right)}{\operatorname{Var}\left(\mathrm{R}_{\mathrm{m}}\right)}$ $\mathrm{E}\left(\mathrm{R}_{\mathrm{m}}\right) \mathrm{E}\left(\mathrm{R}_{\mathrm{m}}\right)$ é o retorno esperado do mercado. $E\left(R_{m}\right)-R_{f} E\left(R_{m}\right)-R_{f}$ é o prêmio de risco, e representa a diferença entre a taxa de retorno esperado do mercado e a taxa de retorno livre de riscos.

Para as pesquisas em contabilidade, a HME e o CAPM possibilitaram que: fosse avaliado o impacto da informação contábil no mercado de capitais, fosse verificada a relação entre os números contábeis e o mercado de capitais, e fossem influenciadas fortemente as pesquisas positivas no campo (WATTS; ZIMMERMAN, 1986; BEAVER, 1998). Desde então, os estudos que relacionam informações contábeis e o mercado de capitais se desenvolveram, principalmente a partir dos trabalhos seminais de Ball e Brown (1968) e Beaver (1968). Hoopwood (2007) destaca que seus contemporâneos no programa de Doutorado em Chicago viveram a efervescência das novidades trazidas pelo paradigma positivista na área da Contabilidade que culminou nos respectivos trabalhos. 
Entre as evidências já conhecidas sobre a utilidade e a relação entre os números contábeis e o mercado de capitais, Lopes (2002) destaca, entre outras: existe uma correlação significativa entre números contábeis e o preço dos títulos, os preços dos títulos variam em decorrência das variações dos fluxos de caixa (FCO) e das acumulações (accruals), e os preços das ações tendem a antecipar os lucros futuros das companhias. Ou seja, a HME demanda que se avalie como o mercado reage à determinada informação (nesse contexto, a informação contábil), para tanto, o CAPM possibilita que se estimem os retornos e se compare o efeito da divulgação nos retornos pré e pós-divulgação (e.g.).

\section{2 TRANSPARÊNCIA E QUALIDADE DAS INFORMAÇÕES CONTÁBEIS NO CONTEXTO DA GOVERNANÇA CORPORATIVA}

A Governança Corporativa consiste em um conjunto de práticas utilizadas pelas empresas com o intuito de se restringir o comportamento oportunista dos gestores e alinhar os objetivos destes com os dos acionistas (WERDER, 2014). Essa área de pesquisa ganhou relevância a partir dos clássicos de Berle e Means (1932), Coase (1937) e Jensen e Meckling (1976). O surgimento das grandes corporações e a separação entre a propriedade e o controle implicaram questionamentos sobre como a gestão era conduzida e se de fato a maximização do valor era a prioridade dos gestores, isso porque a natureza do homem, agregada a anomalias de mercado como a assimetria informacional e o oportunismo dos agentes, podem em alguma medida, reduzir ou inviabilizar a obtenção do objetivo inicial da relação entre principal e agente, ou seja, o agente é contratado com o objetivo de maximizar o valor para o principal (JENSEN; MECKLING, 1976; JENSEN; MECKLING, 1994).

Nesse debate a contabilidade se configura como mecanismo que minimiza a assimetria informacional entre agentes e principais, já que os acionistas, quando da contratação dos gestores, transferem a estes o controle dos ativos e as respectivas informações acerca desses recursos (CHANG; TANG; KRIVOGORSKY, 2011; CORREIA, 2008; BRICKLEY; ZIMMERMAN, 2010; COHEN; KRISHNAMOORTHY; WRIGTH, 2004). Ocorre que dada a natureza dos indivíduos (JENSEN; MECKLING, 1994), a flexibilidade das normas, as escolhas contábeis realizadas pelos agentes e as características qualitativas esperadas pelas demonstrações podem ser prejudicadas (WATTS, 1992; BROWN; TARCA, 2007). 
De acordo com Chaney, Faccio e Parsley (2011), no exercício do objetivo da contabilidade a qualidade da informação contábil é essencial para a redução efetiva da assimetria informacional. Para Gabriel (2011), uma das formas de minimizar o oportunismo dos agentes e melhorar a qualidade da informação é por meio da estrutura de governança. Feng et al. (2011) corroboram que a estrutura de governança reduzirá a possibilidade de oportunismo dos agentes, incluindo restrições no que diz respeito às escolhas contábeis e ao comportamento discricionário deles (WATTS, 1992; MARTINEZ, 2010).

Além disso, o nível de divulgação está associado à melhor estrutura de governança e à maior qualidade da informação contábil (MORRIS; HAM; GRAY, 2011), ou seja, a estrutura de governança melhor afeta significativamente o nível de transparência ou nível de divulgação e, por conseguinte, faz com que o mercado reaja mais rapidamente à divulgação da informação, o que é coerente com a HME (FAMA, 1970; FAMA, 1980; FAMA, 1991). Por outro lado, o nível de divulgação faz com que o mercado reduza a percepção de risco e utilize com maior frequência os números contábeis para a precificação do valor futuro da companhia (VERRECCHIA, 1990; VERRECCHIA, 2001). Tal incorporação dos números contábeis aos modelos de valuation sugere que quanto maior a capacidade explicativa pelos números contábeis do valor de mercado, maior a qualidade da informação contábil (KANG; PANG, 2005).

\section{3 PESQUISAS ANTERIORES}

Os estudos contemporâneos que discutem a temática qualidade das informações contábeis buscam, entre outros, testar proxies de qualidade das informações contábeis, entre outras, a relevância do valor têm sido uma tendência entre os temas que relacionam informação contábil e mercado de capitais (KOTHARI, 2001; BEAVER, 2002). Dechow e Schrand (2010), discutindo sobre a qualidade da informação contábil, afirmam que uma informação contábil será útil quando estas alterarem o comportamento dos investidores, trazendo-lhes informações novas. Afirmam ainda que quanto maior a associação entre o número contábil e o valor de mercado maior a qualidade, entretanto, uma questão premente inquieta os pesquisadores. A maior qualidade medida a partir da relação entre os números contábeis e o valor de mercado, exige uma maior subjetividade, a qual por sua vez, pode comprometer a verificabilidade, o que implica um potencial de redução do objetivo inicial, possibilitando um possível viés na aplicação das normas, mensuração e divulgação dos números contábeis (BALL, 2006). 
Dechow e Schrand (2004) destacam, entretanto, que a utilização de mecanismos de governança melhora o poder de enforcement sobre os agentes, melhorando a qualidade das informações contábeis. Francis, Olsson e Schipper (2006) afirmam que a discricionariedade, um dos componentes que afeta negativamente a qualidade dos resultados decorre: de decisões gerenciais, do sistema de informações, da auditoria, da estrutura de governança e do ambiente regulatório e contábil. Esses fatores, em essência, restringirão ou não o comportamento dos agentes termos de escolhas contábeis e/ou operacionais (WATTS, 1992; MARTINEZ, 2010). Ou seja, os gestores podem tomar decisões que impliquem satisfazer a interesses específicos, logo, pode utilizar a flexibilidade das normas para amparar tais decisões. Nesse sentido, a auditoria, a estrutura de governança e o enforcement das normas minimizam o risco que isso ocorra, ou seja, a independência do auditor ou o tipo de firma de auditoria, associada ao poder disciplinador das normas, e à estrutura de controle e desempenho dos gestores reduzem a possibilidade de anomalias que afetem negativamente a qualidade da informação contábil (ANANDARAJAN et al., 2011; HAW et al., 2012; HAZARIKA; KARPOFF; NAHATA, 2012).

Seguindo a linha das pesquisas estrangeiras, no Brasil, diversos estudos foram desenvolvidos sobre: a melhora da qualidade das informações contábeis em decorrência da adoção das IFRSs, da utilização de estruturas de governanças mais rígidas, da utilização de auditorias do tipo Big Four, da estrutura de propriedade, entre outros (FERNANDES SILVA; MACEDO; MARQUES, 2013; SANTOS; STAROSKY FILHO; KLANN, 2014; SOUSA et al., 2014).

Beiruth etal. (2014) analisaram a associação entre o nível de governança e o timeliness da informações. Os autores observaram dados de 170 empresas que negociaram ações no mercado de capitais nos período de 2012 a 2013. Suas principais conclusões foram de que existe uma associação significativa entre empresas com maiores níveis de governança, ou seja, as práticas de governança diferenciadas afetam positiva e significativamente o timeliness da informação. Esse reconhecimento oportuno potencialmente melhora a qualidade informacional (DECHOW; GE; SCHRAND, 2010).

Oliveira et al. (2014) destacam, entretanto, que as práticas de governança de per si não necessariamente implicam efetividade na melhoria da qualidade das informações contábeis e na assimetria informacional. Os autores apresentaram evidências a partir de um estudo realizado com 383 observações do período de 2010 a 2012. Entre os principais resultados, identificaram que a maioria dos mecanismos de governança utilizada não afetou significativamente a assimetria informacional e tampouco o nível de gerenciamento de resultados. Esses resultados, na perspectiva 
dos autores, sugerem que as práticas de governança analisadas devem ser reavaliadas sob pena de gerarem custos de agência de desnecessários.

Apesar de Oliveira et al. (2014) questionarem a contribuição dos mecanismos de governança individualmente sobre a assimetria e a qualidade da informação, Barros, Soares e Lima (2013) evidenciaram que a estrutura de governança afeta a qualidade da informação contábil mensurada pelo nível de gerenciamento de resultados. Complementarmente, a partir do índice de governança proposto por Leal e Carvalhal-da-Silva (2005), estes verificaram que quanto maior o índice de governança menor o nível de gerenciamento de resultados. Esses achados são coerentes com estudos prévios apresentados pelos autores que sustentavam que uma estrutura de governança mais robusta reduz a possibilidade de ações oportunistas por parte dos gestores, logo, o nível de gerenciamento de resultados tende a reduzir melhorando a qualidade informacional.

No mesmo sentido, a auditoria como validadora da adequação dos procedimentos para o reconhecimento, a mensuração e a divulgação das informações contábeis reduz o risco de ações oportunistas por parte dos agentes. Macedo et al. (2014) evidenciaram que a auditoria melhora a qualidade das informações contábeis. Os autores apresentaram evidências de que o tipo de auditoria (Big Four/Não Big Four) apresenta um ganho marginal na capacidade explicativa dos Lucros e Patrimônio Líquido. A explicação está associada ao papel da auditoria e à reputação dos auditores. Espera-se que auditorias do tipo Big Four tenham maior reputação no mercado de capitais, logo, aqueles números têm maior capacidade informacional, pois são mais confiáveis e consistentemente utilizados pelos analistas nas estimativas do valor da companhia.

Santana et al. (2014), por sua vez, não encontraram evidências de que o tipo de auditor afeta na maior qualidade informacional. Entretanto, observaram que esse nível de qualidade, mensurado a partir da variabilidade do Lucro Líquido (proposto por Barth, Landsman e Lang, 2008) apresentou melhora após a adoção das normas internacionais de contabilidade (IFRSs), ou seja, a adoção de práticas de contabilidade baseadas no Common Law, que demandam o exercício da chamada subjetividade responsável reduziu o nível de gerenciamento, o que melhora a qualidade das informação, por vezes, associado a uma maior capacidade explicativa dos números contábeis (MARTINEZ, 2010).

Outros estudos sobre a temática transparência e qualidade da informação contábil foram realizados no contexto brasileiro e internacional. No contexto brasileiro, destacam-se Almeida, Scalzer e Costa (2008), Baptista (2009), Lima (2010), Jacques et al. (2011), Caixe (2012), Correa et al. (2012), Gatsios (2013), 
Moura, Franz e Cunha (2013), Duarte, Amaral e Azevedo (2014) e Farias et al. (2014). No contexto, internacional, o Quadro 1 apresenta a síntese dos principais estudos realizados em economias emergentes.

Quadro 1 - Síntese de estudos sobre Value Relevance, Transparência e Governança Corporativa realizados em países emergentes

\begin{tabular}{|c|c|c|c|}
\hline Autores & Objetivo & Amostra & Resultados \\
\hline $\begin{array}{l}\text { Dimitro- } \\
\text { poulos e } \\
\text { Asteriou } \\
(2008)\end{array}$ & $\begin{array}{l}\text { Analisar o impacto } \\
\text { da transparência so- } \\
\text { bre a rentabilidade e } \\
\text { testar a existência de } \\
\text { conservadorismo. }\end{array}$ & $\begin{array}{l}\text { Amostra de } 105 \\
\text { empresas não finan- } \\
\text { ceiras do mercado de } \\
\text { capitais de Atenas. }\end{array}$ & $\begin{array}{l}\text { Encontraram evidências de conservadorismo, mas com } \\
\text { fraca tempestividade. Observaram, ainda, que a maior } \\
\text { transparência melhora a informatividade dos números } \\
\text { contábeis das empresas com baixo nível de conserva- } \\
\text { dorismo. }\end{array}$ \\
\hline $\begin{array}{l}\text { Lin e } \\
\text { Hwang } \\
(2010)\end{array}$ & $\begin{array}{l}\text { Analisar a relação } \\
\text { entre a estrutura de } \\
\text { governança, a quali- } \\
\text { dade da auditoria e } \\
\text { o gerenciamento de } \\
\text { resultados. }\end{array}$ & $\begin{array}{l}48 \text { trabalhos que exa- } \\
\text { minaram a relação } \\
\text { entre Governança } \\
\text { Corporativa, quali- } \\
\text { dade da auditoria e } \\
\text { gerenciamento de } \\
\text { resultados. }\end{array}$ & $\begin{array}{l}\text { Observaram que Governança Corporativa, independên- } \\
\text { cia e experiência do conselho de administração têm asso- } \\
\text { ciação negativa com o gerenciamento de resultados. No } \\
\text { mesmo sentido, observaram associação negativa entre } \\
\text { gerenciamento de resultados e tamanho, independência } \\
\text { e experiência do comitê de auditoria, e ainda número de } \\
\text { reuniões deste. Verificaram que a qualidade da auditoria } \\
\text { também reduz o nível de gerenciamento de resultados. }\end{array}$ \\
\hline $\begin{array}{l}\text { Ahmed } \\
(2013)\end{array}$ & $\begin{array}{l}\text { Analisar se a Gover- } \\
\text { nança Corporativa } \\
\text { aumenta a transpa- } \\
\text { rência e a qualidade } \\
\text { dos lucros. }\end{array}$ & $\begin{array}{l}\text { Amostra de } 91 \\
\text { empresas listadas no } \\
\text { mercado de capitais } \\
\text { Russo, com dados } \\
\text { do período de } 1998 \\
\text { a } 2003 \text {. }\end{array}$ & $\begin{array}{l}\text { A qualidade do lucro está associada inversamente ao } \\
\text { nível de acumulações discricionárias. Observou-se, } \\
\text { também, que a adoção das IFRSs aumentou o nível de } \\
\text { transparência. }\end{array}$ \\
\hline $\begin{array}{l}\text { Bokpin } \\
(2013)\end{array}$ & $\begin{array}{l}\text { Identificar as deter- } \\
\text { minantes dos níveis } \\
\text { de evidenciação, } \\
\text { transparência e Value } \\
\text { Relevance. }\end{array}$ & $\begin{array}{l}\text { Amostra de } 27 \text { em- } \\
\text { presas do mercado } \\
\text { de capitais de Gana } \\
\text { no período de } 2003 \\
\text { a } 2008 .\end{array}$ & $\begin{array}{l}\text { Identificou relação positiva, mas insignificante entre } \\
\text { o nível de evidenciação e a Value Relevance. Observou, } \\
\text { ainda, que a adoção das IFRSs, o tamanho da firma, } \\
\text { o nível de endividamento, a qualidade da auditoria e } \\
\text { a lucratividade são variáveis significativas para a explica- } \\
\text { ção do nível de evidenciação. }\end{array}$ \\
\hline $\begin{array}{l}\text { Latridis } \\
(2013)\end{array}$ & $\begin{array}{l}\text { Analisar a relação } \\
\text { entre divulgação am- } \\
\text { biental, qualidade da } \\
\text { evidenciação, estru- } \\
\text { tura de governança e } \\
\text { Value Relevance. }\end{array}$ & $\begin{array}{l}\text { Amostra com } 529 \\
\text { empresas listadas no } \\
\text { mercado de capitais } \\
\text { na Malásia no perío- } \\
\text { do de } 2005 \text { a } 2011 .\end{array}$ & $\begin{array}{l}\text { Identificou relação positiva entre o nível de evi- } \\
\text { denciação ambiental e o desempenho. Verificou-se } \\
\text { que o tamanho da firma, a necessidade de capital, a } \\
\text { lucratividade e os gastos com capital são positivamente } \\
\text { associados à qualidade da evidenciação ambiental. A } \\
\text { maior qualidade da evidenciação ambiental está associa- } \\
\text { da a maior Value Relevance. }\end{array}$ \\
\hline $\begin{array}{l}\text { Siagian, } \\
\text { Siregar e } \\
\text { Rahadian } \\
(2013)\end{array}$ & $\begin{array}{l}\text { Investigar a asso- } \\
\text { ciação entre Gover- } \\
\text { nança Corporativa e } \\
\text { valor de mercado das } \\
\text { firmas. }\end{array}$ & $\begin{array}{l}\text { Amostra com } 125 \\
\text { empresas listadas no } \\
\text { mercado de capitais } \\
\text { da Indonésia. }\end{array}$ & $\begin{array}{l}\text { Observaram que a Governança Corporativa tem asso- } \\
\text { ciação positiva com diferentes proxies de valor da firma, } \\
\text { ou seja, empresas com melhor estrutura de governança } \\
\text { têm maior valor de mercado. Complementarmente, } \\
\text { verificaram que firmas com menor valor de mercado } \\
\text { têm melhor nível de evidenciação do que aquelas com } \\
\text { maiores valores de mercado. }\end{array}$ \\
\hline $\begin{array}{l}\text { Foster, } \\
\text { Kasznik } \\
\text { e Sidhu } \\
(2012)\end{array}$ & $\begin{array}{l}\text { Identificar o efeito } \\
\text { de características } \\
\text { dos países e setores } \\
\text { econômicos sobre } \\
\text { Value Relevance. }\end{array}$ & $\begin{array}{l}\text { Amostra com } 8.825 \\
\text { empresas de } 20 \\
\text { países (emergentes) } \\
\text { com dados do perío- } \\
\text { do de } 1993 \text { a } 2002 \text {. }\end{array}$ & $\begin{array}{l}\text { Observaram que o país e o setor econômico são fatores } \\
\text { que afetam sensivelmente na Value Relevance. Verifica- } \\
\text { ram, ainda que o enforcement das normas, o ambiente } \\
\text { jurídico, o nível de corrupção e o nível de evidenciação } \\
\text { são variáveis significativas para a melhoria da relevância } \\
\text { do valor contábil. }\end{array}$ \\
\hline
\end{tabular}

Fonte: os autores. 


\section{PROCEDIMENTOS METODOLÓGICOS}

O desenvolvimento de uma pesquisa ocorre a partir da utilização de métodos e técnicas que possibilitem ao pesquisador responder adequadamente ao problema de pesquisa proposto. No presente estudo, os métodos e técnicas utilizados serão discutidos nesta seção. O objetivo desta será o de apresentar os procedimentos seguidos para o desenvolvimento do estudo. Diante disso, apresentou-se: classificação da pesquisa, amostra e coleta de dados, e técnica de análise de dados.

A classificação da pesquisa possibilita a adequada compreensão sobre o nível de profundidade e do estudo realizado (HAIR JUNIOR et al., 2005). Consiste em essência na classificação quanto aos objetivos, quanto aos procedimentos e quanto à abordagem do problema (RAUPP; BEUREN, 2006). Quanto aos objetivos, o presente estudo classificou-se como descritivo, pois analisou a relação entre os níveis de transparências das empresas participantes da amostra e a qualidade das informações contábeis. Os estudos descritivos são aqueles que buscam evidenciar características latentes dos fenômenos estudados e/ou testar hipóteses acerca destes (CASTRO, 2006). Quanto aos procedimentos, o trabalho classificou-se como documental e expost-facto, pois utilizou dados das demonstrações contábeis trimestrais do período de 2007 a 2012. Os estudos documentais são aqueles em que as evidências são obtidas a partir de documentos não editados e que possibilitam ao pesquisador responder ao problema de pesquisa proposto (MALHOTRA, 2006). Por fim, quanto à abordagem do problema, o trabalho classificou-se como quantitativo, pois utilizou a análise de regressão com dados em painel para se estudar o fenômeno de interesse. Kerlinger (2009) define os estudos quantitativos como aqueles que utilizam métodos e técnicas matemáticas ou estatísticas para se estudar determinado objeto.

Quanto à amostra e coleta à de dados, foram extraídos em períodos trimestrais do banco de dados da BM\&FBOVESPA no período de 01 de janeiro de 2014 a 03 de março do mesmo ano, que se referem às empresas ganhadoras do Prêmio de Transparência ANEFAC no período de 2007 a 2009 cinco vezes ou mais, totalizando nesse grupo nove empresas. Adicionalmente, selecionou-se um grupo de controle de empresas que não ganhou o Prêmio de Transparência ANEFAC. A seleção das empresas desse grupo foi a partir dos setores econômicos das empresas do grupo de interesse (empresas ganhadoras do prêmio).

Como técnica de análise, utilizou-se a regressão múltipla com dados em painel. A análise de regressão é uma técnica estatística utilizada na estimativa do comportamento dos fenômenos estudados. Wooldridge (2010) afirma que a análise de regressão é útil 
para se testar empiricamente a relação entre variáveis. Usualmente utilizadas em estudos com abordagem positivista em contabilidade (WATTS; ZIMMERMAN, 1986), têm contribuído para os estudos no campo da Contabilidade e Finanças desde o fim do ano 1958 (BEAVER, 1998). Nos últimos anos, a utilização da análise de regressão com a utilização de dados longitudinais têm crescido substancialmente (FÁVERO, 2013). A utilização de dados longitudinais, também denominada painel, contribui para a redução do efeito da heterogeneidade, do maior conjunto de informações sobre as variáveis de interesse, do maior grau de liberdade, da menor colinearidade e da maior eficiência na estimação (MARQUES 2000 apud FÁVERO, 2013).

Nesse contexto, o presente estudo utilizou a técnica de análise de regressão com dados em painel para a estimação da relação entre Valor de Mercado por Ação (VMA) (variável explicada) e Lucro por Ação (LPA) e Patrimônio Líquido por Ação (PLA), variáveis explicativas. O modelo econométrico utilizado considera que o Lucro por Ação (LPA $i t_{0} i t_{0}$ ) e o Patrimônio Líquido por Ação (PLA $\left.i t_{0}\right) i t_{0}$ ) do período anterior são variáveis úteis para a explicação do Valor de Mercado da Ação (VMA $\left.i t_{+1} i t_{+1}\right)$ do período seguinte. Os estudos anteriores apresentados na seção 2.3 utilizaram o modelo citado e têm apresentado consistência nos resultados.

$$
\begin{gathered}
V M A_{i t+1}=\alpha_{0}+\beta_{1} L P A_{i t_{0}}+\beta_{2} P L A_{i t_{0}}+\varepsilon_{i t} \\
V M A_{i t+1}=\alpha_{0}+\beta_{1} L P A_{i t_{0}}+\beta_{2} P L A_{i t_{0}}+\varepsilon_{i t}
\end{gathered}
$$

Onde:

$V M A_{i t} V M A_{i t}$ : Valor de mercado das ações da i-ésima empresa no momento t;

$L P A_{i t} L P A_{i t}$ : Lucro por ação da i-ésima empresa no momento t;

$P L A_{i t} P L A_{i t}$ : Patrimônio líquido por ação da i-ésima empresa no momento t;

$\alpha_{0}, \beta_{1}, \beta_{2} \alpha_{0}, \beta_{1}, \beta_{2}$ : Parâmetros estimados da regressão;

$\varepsilon_{i t} \varepsilon_{i t}$ : Termo de erro da regressão.

Espera-se que os números contábeis expliquem em alguma medida o valor de mercado dos títulos (DECHOW; GE; SCHRAND, 2010), ou seja, que os parâmetros 
tendam a ter sinais positivos e significativos. Se a melhor capacidade informacional está relacionada à fidedignidade e à comparabilidade, então é esperado que o nível de informações divulgadas, obrigatórias ou voluntárias (VERRECCHIA, 1990; VERRECCHIA, 2001) bem como a estrutura de governança das empresas estejam associados à melhoria da qualidade dos números contábeis (BRICKLEY; ZIMMERMAN, 2010; CHANG; TANG; KRIVOGORSKY, 2011; BROWN; BEEKES; VERHOEVEN, 2011; AHMED, 2013). Assim, esperava-se que os coeficientes dos modelos separados entre os grupos tivessem características diferentes, pois no modelo com as empresas ganhadoras do Prêmio Transparência ANEFAC, a intensidade dos parâmetros deve ser maior e estatisticamente significativa quando comparada ao modelo que continha apenas as empresas não ganhadoras. Ademais, a observância de maior capacidade informacional ocorre efetivamente pela capacidade explicativa do modelo medida pelo $\mathrm{R}^{2}$. Desse modo, espera-se que o resultado da regressão para o grupo das empresas ganhadoras do prêmio apresente um $\mathrm{R}^{2}$ maior que o grupo das empresas não ganhadoras.

\section{ANÁLISE DOS DADOS}

\section{1 ESTATÍSTICA DESCRITIVA}

Inicialmente, analisou-se as características das variáveis utilizadas no modelo. Verificou-se que as empresas que ganharam o Prêmio ANEFAC apresentaram maiores médias $(\mu)$ de VMA e LPA e menor média $(\mu)$ de PLA. Esses resultados sugerem que as empresas com maiores níveis de transparência apresentam melhores desempenhos em duas das principais métricas utilizadas pelo mercado (Valor de Mercado e Lucro) e que, por sua vez, essas empresas apresentam menores níveis de PL. Tais características podem estar associadas à distribuição de forma mais consistente dos resultados auferidos, captando dinheiro no mercado financeiro para o financiamento dos seus projetos futuros, o que é coerente com a Teoria da Hierarquização das Fontes de Financiamento (MYERS; MAJLUF, 1984).

Alémdisso, osresultadosmostramque empresasmaistransparentesapresentaram as variáveis com menor dispersão, pois em todas elas o Desvio padrão $(\sigma)$, o Coeficiente de Variação $(\sigma / \mu)$ e a amplitude foram menores, sugerindo maior homogeneidade dos dados daquele grupo. Dada a diferença nas características das variáveis, realizaram testes de hipóteses para a verificação da significância estatística das respectivas diferenças, observando-se que as diferenças entre os grupos foram significativas para as variáveis 
PLA e VMA ao nível de significância de 1\%, não havendo diferença estatisticamente significativa para a variável LPA. A Tabela 1 sintetiza as características mencionadas anteriormente, bem como os resultados dos testes estatísticos realizados.

Tabela 1 - Estatística descritiva das variáveis de relevância do valor

\begin{tabular}{|c|c|c|c|c|c|c|}
\hline Grupos & $\mathrm{n}$ & Média & $\begin{array}{l}\text { Desvio- } \\
\text {-padrão }\end{array}$ & $\begin{array}{l}\text { Coef.de } \\
\text { Variação }\end{array}$ & Mínimo & Máximo \\
\hline $\begin{array}{l}\text { Valor de Mercado } \\
\text { por Ação }\end{array}$ & & & & & & \\
\hline $\begin{array}{l}\text { Empresas vence- } \\
\text { doras }\end{array}$ & 279 & 25,7900 & 18,4185 & 0,7142 & 5,6300 & 136,8000 \\
\hline $\begin{array}{l}\text { Empresas não } \\
\text { vencedoras }\end{array}$ & 286 & 22,5799 & 31,3733 & 1,3894 & 0,0500 & 122,0000 \\
\hline Total da amostra & 565 & 24,1651 & 25,8296 & 1,0689 & 0,0500 & 136,8000 \\
\hline Lucro por Ação & & & & & & \\
\hline $\begin{array}{l}\text { Empresas vence- } \\
\text { doras }\end{array}$ & 279 & 0,6181 & 0,9126 & 1,4766 & $\begin{array}{l}- \\
4,1777\end{array}$ & 3,5889 \\
\hline $\begin{array}{l}\text { Empresas não } \\
\text { vencedoras }\end{array}$ & 286 & 0,3372 & 3,8755 & 11,4943 & - & 54,2208 \\
\hline Total da amostra & 565 & 0,4759 & 2,8319 & 5,9511 & $\begin{array}{l}- \\
25,1554\end{array}$ & 54,2209 \\
\hline $\begin{array}{l}\text { Patrimônio Lí- } \\
\text { quido por Ação }\end{array}$ & & & & & & \\
\hline $\begin{array}{l}\text { Empresas vence- } \\
\text { doras }\end{array}$ & 279 & 15,9050 & 8,9880 & 0,5651 & 0,0464 & 54,0028 \\
\hline $\begin{array}{l}\text { Empresas não } \\
\text { vencedoras }\end{array}$ & 286 & 17,1532 & 51,6899 & 3,0134 & - & 288,1684 \\
\hline Total da amostra & 565 & 16,5368 & 37,2873 & 2,2548 & 49,5882 & 288,1683 \\
\hline
\end{tabular}

Fonte: os autores.

${ }^{1}$ Para a Variável LPA o Teste $t$ para uma amostra H_0: $\mu>1$ não pode ser rejeitado ( $p$-valor:1,00); ${ }^{2}$ Para a Variável PLA o Teste $t$ para uma amostra $\mathrm{H}_{0}: \mu=16$ não pode ser rejeitado (p-valor:0,7323); ${ }^{3}$ Para a Variável VMA o Teste $t$ para uma amostra $\mathrm{H}_{0}: \mu=24$ não pode ser rejeitado (p-valor:0,8793); ${ }^{4}$ Para a Variável LPA o Teste $F$ para a variância entre os grupos com $\mathrm{H}_{0}$ :Diff $>1$ não pode ser rejeitado ( $p$-valor:0,000). Test $t$ para a diferença entre as médias com $\mathrm{H}_{0}:$ Diff $>0$ rejeitada ( $p$-valor: 0,8830$) ;{ }^{5}$ Para a Variável PLA o Teste $F$ para a variância entre os grupos com $\mathrm{H}_{0}$ :Diff $>1$ não pode ser rejeitada ( $p$-valor:0,000). Test $t$ para a diferença entre as médias com $\mathrm{H}_{0}$ :Diff $<0$ rejeitada ( $p$-valor: 0,6531$)$. Test $t$ para diferença entre as médias com $\mathrm{H}_{0}:$ Diff $>0$ rejeitada ( $p$-valor: 0,8830$) .{ }^{6}$ Para a Variável VMA o Teste $F$ para a variância entre os grupos com $\mathrm{H}_{0}:$ Diff $>1$ não pode ser rejeitada ( $p$-valor:0,000). Test $t$ para a diferença entre as médias com $\mathrm{H}_{0}:=$ Diff $<0$ não pode ser rejeitada ( $p$-valor: 0,6531$)$. 
Posteriormente, conforme se pode observar na Tabela 2, analisou-se a correlação entre as variáveis do modelo. Observou-se que as correlações entre as variáveis do grupo de empresas ganhadoras apresentaram significância estatística em todas as variáveis com a correlação fraca a mediana, enquanto nas empresas não ganhadoras a existência de correlação significativa entre PLA e LPA com coeficiente fraco. Esses resultados indicam que o LPA e o PLA de empresas com maiores níveis de transparência apresentam comportamento mais associado ao comportamento do VMA, ou seja, se o LPA e o PLA aumentarem, o VMA tenderá a aumentar (BROWN; BEEKES; VERHOEVEN, 2011). Já para as empresas não ganhadoras esse movimento não ocorre de forma significativa, sugerindo uma aleatoriedade na relação entre essas variáveis.

Tabela 2 - Correlação entre as variáveis de relevância do valor

\begin{tabular}{|c|c|c|c|c|c|c|c|c|c|}
\hline \multirow{2}{*}{ Variáveis } & \multicolumn{3}{|l|}{ Todas } & \multicolumn{3}{|c|}{ Vencedoras } & \multicolumn{3}{|c|}{ Não Vencedoras } \\
\hline & LPA & PLA & VMA & LPA & PLA & VMA & LPA & PLA & VMA \\
\hline $\begin{array}{l}\text { Lucro p/ação } \\
\text { (LPA) }\end{array}$ & 1,0000 & $0,1356^{\star}$ & $0,1201^{\star}$ & 1,0000 & $0,5280^{\star \star}$ & $0,561^{\star \star}$ & 1,0000 & $0,1210^{\star}$ & 0,0640 \\
\hline $\begin{array}{l}\text { Patrimônio } \\
\text { p/ação (PLA) }\end{array}$ & $0,1356^{\star}$ & 1,0000 & $0,1500^{\star}$ & $0,5280^{\star \star}$ & 1,0000 & $0,631^{\star \star}$ & $0,1210^{\star}$ & 1,0000 & 0,1150 \\
\hline $\begin{array}{l}\text { Valor Mer- } \\
\text { cado p/ação } \\
\text { (VMA) }\end{array}$ & $0,1201^{\star}$ & $0,1500^{\star}$ & 1,0000 & $0,5610^{\star \star}$ & $0,6310^{\star \star}$ & 1,0000 & 0,0640 & 0,1150 & 1,0000 \\
\hline
\end{tabular}

\section{2 ANÁLISE DO MODELO}

Para testar a pressuposição do presente trabalho, aplicou-se a técnica estatística de regressão linear múltipla com dados em painel. Analisando-se os resultados obtidos, pode-se então confirmar (ou não) a pressuposição anteriormente formulada. A análise consistiu na utilização de três modelos específicos, a saber: um com todas as empresas (utilizando o modelo com efeitos aleatórios), um apenas com as empresas ganhadoras do Prêmio ANEFAC (utilizando o modelo com efeitos fixos) e outro apenas com empresas não vencedoras (utilizando o modelo com efeitos aleatórios).

Observou-se que quando utilizado o modelo com todas as empresas, a capacidade explicativa dos números contábeis foi baixa $\left(R^{2} R^{2}=2,8 \%\right)$ com o intercepto e o LPA apresentando significância estatística ao nível de 1\% para ambas 
as variáveis. Porém, o PLA não apresentou associação significativa, sugerindo que para as empresas participantes da amostra o PLA não possui capacidade explicativa do valor de mercado das ações. Esse modelo, que inicialmente utilizou como variável dummy para controlar o efeito do nível de transparência (1 para as ganhadoras e 0 para as não ganhadoras), teve que ser modificado retirando as respectivas variáveis, pois a inclusão de tais variáveis reduziu a capacidade explicativa, além de fazer com que apenas o LPA fosse significativo a um nível de $10 \%$. Tais resultados estão convergentes com trabalhos que não observaram efeito significativo dos mecanismos de governança e transparência sobre a relevância dos números contábeis (BEIRUTH et al., 2014). Apesar disso, a maioria dos estudos encontram evidências de que os instrumentos de governança reduzem o risco de oportunismo dos agentes e por conseguinte terão números contábeis mais úteis à avaliação do valor dos títulos, ou seja, têm maior qualidade (BRICKLEY; ZIMMERMAN, 2010; BROWN; BEEKES; VERHOEVEN, 2011).

Tabela 3 - Estatísticas de relevância do valor com dados em painel

\begin{tabular}{llll}
\hline & Amostra & \multicolumn{2}{l}{ Agrupamento em empresas } \\
\cline { 3 - 4 } & & Ganhadoras & Não ganhadoras \\
\hline Modelo do painel & Efeitos aleatórios & Efeitos fixos & Efeitos aleatórios \\
Observações & 565 & 279 & 286 \\
Grupo & 18 & 9 & 9 \\
\hline$R^{2}$ & & & \\
\hline Entre & 0,2330 & 0,2858 & 0,0119 \\
Dentre & 0,1163 & 0,8839 & 0,0561 \\
Total & 0,0280 & 0,4678 & 0,0001 \\
Teste Wald $\left(R^{2} R^{2}\right)$ & $13.35^{\star}$ & $53.61^{\star}$ & 0,0337 \\
\hline$\alpha$ & 0,2320 & 0,1144 & 0,0222 \\
p-valor & 0,0000 & 0,0000 & $-0,0540$ \\
$\beta_{1}$ & 0,6296 & 0,0592 & 0,2910 \\
p-valor & $-0,0020$ & 0,0000 & $-0,0980$ \\
$\beta_{2}$ & 0,2546 & 0,6724 & 0,0094 \\
p-valor & $-0,1310$ & 0,0000 & $-0,5230$ \\
\hline$\sigma \_u$ & 22,5714 & 6,0856 & 34,6318 \\
$\sigma-\mathrm{e}$ & 13,1309 & 12,6750 & 11,3623 \\
P & 0,7471 & 0,1873 & 0,9028 \\
\hline Fonte: & & & \\
\hline
\end{tabular}

Fonte: os autores.

Nota: ${ }^{\star},{ }^{\star \star},{ }^{\star \star}$ Significativo a $1 \%, 5 \%$ e $10 \%$, respectivamente. (a) Para a definição do melhor modelo o teste $\mathrm{F}$ de Chow para a comparação entre os modelos Pooled versus Efeitos fixos em que: $\mathrm{H}_{0}: \beta_{1}=\beta_{2}=\ldots B_{\mathrm{k}} \ldots B_{\mathrm{k}}=B_{0} B_{0}$ (Regra de decisão: $\mathrm{F}<0,10$ - rejeita-se $\mathrm{H}_{0}$ ). Para a comparação entre os modelos Pooled versus Efeitos aleatórios, utilizou-se o teste Breush 
Pagan em que: $H_{0}: \sigma_{\varepsilon}^{2} H_{0}: \sigma_{\varepsilon}^{2}=0$ (Regra de decisão: $\mathrm{LM}<0,10-$ rejeita-se $\mathrm{H}_{0}$ ). Por fim, para a comparação entre os modelos com Efeitos aleatórios versus Efeitos fixos, realizaram os testes de Hausman (Regra de decisão: $x^{2}$ Regra de decisão: $x^{2}<0,10$ - rejeita-se $\mathrm{H}_{0}$ ) (FÁVERO et al., 2014).

Nesse sentido, de modo a se observarem diferenças na capacidade explicativa das empresas de ambos os grupos e dada a ineficiência do modelo completo, separam-se as empresas nos respectivos grupos, tendo melhorado substancialmente o desempenho geral do modelo e as inferências associadas se tornaram coerentes com as expectativas teóricas acerca do fenômeno. Diante disso, observou-se que a capacidade explicativa total do modelo para empresas ganhadoras do Prêmio ANEFAC foi superior a das empresas não ganhadoras (46,78\% e 0,010\%, respectivamente). Além disso, verificou-se que todas as variáveis explicativas foram significativas estatisticamente na capacidade de explicação do VMA a um nível de 1\% para as empresas com maior nível de transparência. Os resultados possibilitam afirmar que a cada variação de uma unidade monetária no LPA e no PLA médio, espera-se aumentos marginais no VMA.

Já no modelo testado composto pelas empresas não ganhadoras do prêmio ANEFAC, o intercepto $(\alpha)$ e o coeficiente de inclinação $\left.\left(\beta_{1}\right) \beta_{1}\right)$ foram estatisticamente significativos ao nível de $10 \%$. Além disso, a intensidade do efeito dessas variáveis sobre o VMA é inferior àquela observada no modelo composto apenas com empresas com maior nível de transparência. Esses resultados são coerentes com os estudos que evidenciaram melhoria na capacidade informacional, dada a existência de mecanismos de governança mais robustos como Ahmed (2013), Chang, Tang e Krivogorsky (2011), Martinez (2010), Morris, Ham e Gray (2011) e Werder (2014).

\section{CONSIDERAÇÕES FINAIS}

O objetivo do presente estudo foi analisar a relação entre a qualidade informacional e o nível de transparência das empresas. O estudo é de natureza descritiva, documental (ex post facto) e com abordagem quantitativa; analisou dados de 18 empresas participantes da BM\&F Bovespa com dados trimestrais (28 trimestres) no período de 2007 a 2013. A amostra foi composta por nove empresas vencedoras do Prêmio de Transparência da ANEFAC mais que cinco vezes entre o período e 
outras nove do mesmo subsetor (ou setor econômico) conforme a BM\&F Bovespa. A análise foi realizada por meio do modelo de regressão (com dados em painel) proposto por Lara e Mora (2004). Entre os principais resultados, verificou-se que o grupo das empresas vencedoras apresentou menor dispersão dos dados, demonstrando maior homogeneidade dos dados, ou seja, o LPA, o PLA e o VMA foram mais homogêneos comparativamente aos do grupo de empresas não vencedoras, do Prêmio ANEFAC. Além disso, observaram-se correlações maiores e significativas no grupo das empresas vencedoras, o que reforça maior capacidade explicativa dos números contábeis das empresas com maiores níveis de transparência. Por fim, observou-se que os números contábeis (LPA e PLA) foram mais relevantes para a explicação dos valores de mercado das empresas ao nível de 1\% de significância para as empresas vencedoras. Entre as não vencedoras, apenas o LPA foi estatisticamente significante ao nível de $10 \%$. Os resultados são convergentes com os encontrados em pesquisas anteriores (KANG; PANG, 2005; MORRIS; HAM; GRAY, 2011; SANTOS; STAROSKY FILHO; KLANN, 2014; MARTINEZ, 2010).

A despeito da convergência dos resultados observados quando separados os grupos de empresas, o modelo com todas as empresas agrupadas sem a devida identificação de efeito significativo como na maior parte da literatura analisada, pode decorrer de viés na estimativa em decorrência de omissão de variáveis representativas. No contexto estrangeiro, Dimitroupolos e Asteriou (2008), Lin e Hwang (2010), Foster, Kasznik e Sidhu (2012), Bokpin (2013), Latridis (2013), Siagian, Siregar e Rahadian (2013) encontraram evidências de que a transparência afeta significativa e positivamente a qualidade das demonstrações contábeis. No presente estudo, tais relações foram observadas quando analisados separadamente os grupos de empresas estudadas (ganhadoras e não ganhadoras do Prêmio ANEFAC), entretanto, trata-se de uma amostra limitada, cabendo melhorias no sentido de se compreender: instrumentos de governança que efetivamente geram maior percepção de transparência, se setores econômicos e nível de competitividade afetam a maior percepção de transparência, entre outras variáveis possíveis de terem sido omitidas, como: tipo de auditoria, mudança do auditor, (3) variabilidade dos resultados, (4) republicação ou não das demonstrações, (5) independência do auditor, etc.

A adoção das IFRSs no contexto brasileiro adveio do interesse em se adotarem práticas de contabilidade que melhorem a qualidade das demonstrações contábeis (DECHOW; SCHRAND, 2004). Adicionalmente, sabe-se que a estrutura de governança e a transparência potencializam a maximização do valor para o acionista (JENSEN; MECKLING, 1976; VERRECCHIA, 1990; VERRECCHIA, 2001), o 
que conjuntamente fortalece a associação entre os números contábeis e o valor de mercado dos títulos. Os resultados encontrados sugerem que, de fato, o nível de transparência atribui maior significância dos números contábeis na capacidade de explicação do valor de mercado, demandando, entretanto, estudos complementares conforme mencionado anteriormente, de modo a se entender especificamente como outras variáveis se relacionam com a qualidade informacional dos números contábeis.

\section{REFERÊNCIAS}

AHMED, S. Measuring quality of reported earnings' response to corporate governance reforms in Russia. Journal of Accounting in Emerging Economies, v. 3, n. 1, p. 21-46, 2013.

ALMEIDA, J. C. G.; SCALZER, R. S.; COSTA, F. M. Níveis diferenciados de governança corporativa e grau de conservadorismo: estudo empírico em companhias abertas listadas na Bovespa. RCO - Revista Contabilidade e Organizações, Ribeirão Preto, v. 2, n. 2, p. 118-131, jan./abr. 2008.

ANANDARAJAN, A. et al. Value Relevance of Banks: global evidence. Rev. Quant. Financ. Acc., n. 33, p. 33-55, 2011.

BALL, R.; BROWN, P. An empirical evaluation of accounting numbers. Journal of Accounting Research, Chicago, p. 159-178, Aug. 1968.

BALL, R. International Financial Reporting Standards (IFRS): Pros and Cons for Investors. Accounting and Business Research, v. 36, n. 1, p. 5-27, 2006.

BAPTISTA, E. M. Ganhos em transparência versus novos instrumentos de manipulação: o paradoxo das modificações trazidas pela Lei n. 11.638. RAE, São Paulo, v. 49, n. 2, p. 234-239, abr./jun. 2009.

BARROS, M. E.; SOARES, R. O.; LIMA, G. A. F. A relação entre Governança Corporativa e gerenciamento de resultados em empresas brasileiras. RCO Revista Contabilidade e Organizações, Ribeirão Preto, n. 19, p. 27-39, 2013. Disponível em:< http://dx.doi.org/10.11606/rco.v7i19.55509>. Acesso em: 30 abr. 2014.

BARTH, M. E.; LANDSMAN, W. R.; LANG, M. H. International accounting standards and accounting quality. Journal of Accounting Research, v. 46, n. 3, p. 467-498, 2008. Disponível em: <http://dx.doi.org/10.1111/j.1475679X.2008.00287.x>. Acesso em: 10 abr. 2014. 
BEAVER, W. H. Financial Reporting: An Accounting Revolution. 3. ed. São Paulo: Prentice Hall, 1998. 180 p.

BEAVER, W. H. Perspective on Recent capital Market Research. The Accounting Review, v. 77, n. 2, p. 453-474, Apr. 2002.

BEAVER, W. H. The information content of annual earnings announcements. Journal of Accounting Research, p. 67-92, 1968.

BEIRUTH, A. X. et al. Níveis diferenciados de governança e disclosure timeliness: um estudo exploratório no mercado brasileiro. Gestão, Finanças e Contabilidade, Salvador, v. 4, n. 1, p. 77-89, jan./abr. 2014.

BERLE, A. A.; MEANS, G. C. A moderna sociedade anônima e a propriedade privada. Tradução Dinah de Abreu Azevedo. São Paulo: Cultura, 1932. $335 \mathrm{p}$.

BERNSTEIN, P. A história do Mercado de Capitais: o impacto da ciência e da tecnologia nos investimentos. Rio de Janeiro: Elsevier, 2008. 298 p.

BOKPIN, G. A. Determinants and value relevance of corporate disclosure: evidence from the emerging capital market of Ghana. Journal of Applied Accounting Research, v. 14, n. 2, p. 127-146, 2013.

BRICKLEY, J. A.; ZIMMERMAN, J. L. Corporate Governance Myths: comments on Armstrong, Guay, and Weber. Journal of Accounting and Economics, v. 50, n. 2, p. 235-245, 2010.

BROWN, P.; BEEKES, W.; VERHOEVEN, P. Corporate governance, accounting and finance: a review. Accounting \& Finance, v. 51, n. 1, p. 96-172, Mar. 2011.

BROWN, P; TARCA, A. Achieving High Quality, Comparable Financial Reporting: A Review of Independent Enforcement Bodies in Australia and the United Kingdom. ABACUS, Sydney, v. 4, p. 438-473, 2007.

CAIXE, D. F. Relação entre a dinâmica entre a estrutura de propriedade e controle e o valor de mercado corporativo no Brasil: análise da primeira década do século XXI. 2012. 138 p. Dissertação (Mestrado em Administração das Organizações)-Universidade de São Paulo, Ribeirão Preto, 2012.

CARVALHAL DA SILVA, A. L.; LEAL, R. P. C. Corporate Governance Index, Firm Valuation and Performance in Brazil. RBFin - Revista Brasileira de Finan;as, Rio de Janeiro, v. 3, n. 1, p. 1-18, 2005. 
CASTRO, C. M. A prática da pesquisa. 2. ed. São Paulo: Pearson Prentice Hall, 2006. $190 \mathrm{p}$.

CHANEY, P. K.; FACCIO, M.; PARSLEY, P. The quality of accounting informationin politically connected. Journal of Accounting and Economics, v. 51, p. 58-76, 2011.

CHANG, J. C.; TANG, A. P.; KRIVOGORSKY, V. The impacts of SOX and SEC investigation on the corporate governance of option backdating firms. Advances in Accounting, incorporating Advances in International Accounting, n. 27, p. 205- 212, 2011.

COASE, R. H. The nature of firm. Economica, v. 4, n. 16, p. 386-405, Nov. 1937.

COHEN, J. R.; KRISHNAMOORTHY, G.; WRIGTH, A. The corporate Governance Mosaic and Financial Reporting Quality. Journal of Accounting Literature, p. 87-152, 2004.

CORREA, A. C. C. et al. A relevância da informação contábil na identificação de empresas criadoras de valor: um estudo do setor de energia elétrica brasileiro. Revista Contemporânea de Contabilidade, Florianópolis, v. 9, n. 18, p. 137166, jun./dez. 2012.

CORREIA, L. F. Um índice de governança para as empresas brasileiras. 2008. 269 p. Tese (Doutorado em Administração)-Centro de Pós-graduação e Pesquisa em Administração, Universidade Federal de Minas Gerais, Belo Horizonte, 2008.

DECHOW, P. M.; GE, W.; SCHRAND, C. Understanding earnings quality: a review of the proxies, their determinants and their consequences. Journal of Accounting and Economics, p. 344-401, 2010.

DECHOW, P. M.; SCHRAND, C. M. Earnings Quality. Virginia: The Research Foundation of CFA Institute, 2004. $152 \mathrm{p}$.

DIMITROUPOLOS, P. E.; ASTERIOU, D. Timeliness, conservatism and financial transparent firms under Greek accounting setting. Review of Accounting and Finance, v. 7, n. 3, p. 252-269, 2008.

DUARTE, A. M. P.; AMARAL, I. S.; AZEVEDO, G. M. C. Adoção das IFRS e a Qualidade da Contabilidade: uma análise. In: CONGRESSO USP DE CONTROLADORIA E CONTABILIDADE, 14., 2014, São Paulo. Anais... São Paulo, 2014. Disponível em: < http://congressousp.fipecafi.org/web/ artigos142014/266.pdf> . Acesso em: 30 abr. 2014. 
ECKER, F. et al. Estimation sample selection for discretionary accruals models. Journal of Accountingand Economics, v. 56, p. 190-211, 2013.

FAMA, E. Agency problems and Theory of the Firms. Journal of Political Economy, Chicago, v. 88, p. 288-307, Apr. 1980.

FAMA, E. Efficiente Capital Markets II. The Journal of Finance, v. 46, n. 5, p. 1575-1617, Dec. 1991.

FAMA, E. Efficient Market: A Review of Theory and Emprirical Work. Journal of Economics, p. 383-417, Apr. 1970.

FARIAS, J. B. et al. Impactos da adoção das IFRS nas Demonstrações Consolidadas dos Bancos listados na BM\&FBovespa. Revista Universo Contábil, Blumenau, v. 10, n. 2, p. 63-83, abr./jun. 2014.

FÁVERO, L. P. L. Dados em painel em contabilidade e finanças. Brazilian Business Review, Vitória , v. 10, n. 1, p. 131-156, jan./mar. 2013.

FÁVERO, L. P. L. et al. Métodos Quantitativos com Stata. Rio de Janeiro: Elsevier, 2014. 248 p.

FENG, M. et al. Why do CFOs become involved in material accounting manipulations? Journal of Accounting and Economics, v. 52, p. 21-36, 2011.

FERNANDES SILVA, A.; MACEDO, M. A. S.; MARQUES, J. A. V. C. Análise da relevância da informação contábil no setor brasileiro de energia elétrica no período de 2005-2009: um estudo comparativo entre as informações de lucro e de caixa. Contabilidade Vista \& Revista, Belo Horizonte, v. 24, n. 2, p. 63-90, abr./jun. 2013.

FOSTER, G.; KASZNIK, R.; SIDHU, B. K. International equity valuation: the relative importance of country and industry factors versus company-specific financial reporting information. Accounting \& Finance, v. 52, n. 3, p. 767-817, Sep. 2012.

FRANCIS, J.; OLSSON, P.; SCHIPPER, K. Earnings quality. Foundation and Trends in Accounting, v. 1, n. 4, p. 259-340, 2006.

GABRIEL, F. Impacto da adesão às práticas recomendadas de Governança Corporativa no índice de qualidade da informação contábil. 2011. 128 p. Tese (Doutorado em Ciências Contábeis)-Universidade de São Paulo, São Paulo, 2011. 
GATSIOS, R. C. Acurácia e dispersão das estimativas dos analistas do mercado de capitais: impacto da adoção do padrão IFRS sobre a qualidade preditiva da informação contábil. 2013. 105 p. Dissertação (Mestrado em Controladoria e Contabilidade)- Universidade de São Paulo, Ribeirão Preto, 2013.

HAIR JUNIOR, J. F. et al. Fundamentos de métodos de pesquisa em administração. Porto Alegre: Bookman, 2005.

HAW, I. et al. Investor protection and price informativeness about future earnings: international evidence. Rev. Account Stud., v. 17, p. 389-419, 2012.

HAZARIKA, S.; KARPOFF, J. M.; NAHATA, R. Internal Corporate Governance, CEO Turnover, and earnings management. Journal of Financial Economics, v. 104, p. 44-69, 2012.

HOOPWOOD, A. Whither accounting research. The Accounting Review, v. 82, n. 5, p.1365-1374, 2007.

JACQUES, F. V. S. et al. Contabilidade e a sua relevância nas boas práticas de Governança Corporativa. Revista Contemporânea em Contabilidade, Florianópolis, v. 8, n. 16, p. 37-63, jul./dez. 2011.

JENSEN, M. C.; MECKLING, W. H. The nature of man. Journal of Applied Corporate Finance, Boston, v. 7, n. 2, p. 4-19, 1994.

JENSEN, M. C.; MECKLING, W. H. Theory of the firm: managerial behavior, agency costs and ownership structure. Journal of Financial and Economics, v. 3, n. 4, p. 305-360, Oct. 1976.

KANG, T.; PANG, Y. H. Economic Development and Value-Relevance of Accounting Information - A Disclosure Transparency Perspective. Review of Accounting and Finance, v. 4, n. 1, p. 5-31, 2005.

KERLINGER, F. N. Metodologia da pesquisa em ciências sociais. 11. ed. São Paulo: EPU, 2009.

KOTHARI, S. P. Capital markets research in accounting. Journal of Accounting and Economics, v. 31, p. 105-231, 2001.

LATRIDIS, G. E. Environmental disclosure quality: evidence on environmental performance, corporate governance and value relevance. Emerging Market Review, v. 14, p. 55-75, 2013. 
LEAL, R. P. C. E CARVALHAL DA SILVA, A. Corporate Governance and Value in Brazil (and in Chile) (May 2005). Disponível em: SSRN: < http://dx.doi. org/10.2139/ssrn.726261>. Acesso em: 03 maio 2014.

LIMA, J. B. N. A relevância da informação contábil e o processo de convergência para as normas IFRS no Brasil. 2010. Tese (Doutorado em Ciências Contábeis)Programa de Pós-Graduação em Controladoria e Contabilidade, FEA/USP, São Paulo, 2010.

LIN, J. W.; HWANG, M. L. Audit Quality, Corporate Governance, and Earnings Management: a Meta-Analisys. International Journal of Auditing, v. 14, p. 57$77,2010$.

LOPES, A. B. A Informação contábil e o Mercado de Capitais. São Paulo: Pioneira Thomson Learning, 2002.

MACEDO, A. S. et al. Impacto de Mecanismos de Auditoria na Precificação de Ações: evidências sob a perspectiva da relevância e da tempestividade para o ano de 2010 no Brasil. Contabilidade, Gestao e Governanca, Brasília, DF, v. 17, n. 3, p. 127-144, 2014.

MACKENZIE, B. et al. IFRS 2012: interpretação e aplicação. Porto Alegre: Bookman, 2013. 1097 p.

MALHOTRA, N. K. Pesquisa de Marketing: uma orientação aplicada. 4. ed. Porto Alegre: Bookman, 2006.

MARTINEZ, A. L. Quando o conselho de administração e a auditoria evitam o gerenciamento de resultados? Evidências Empíricas para empresas Brasileiras. RIC - Revista de Informação Contábil, Pernambuco, v. 4, n. 1, p. 76-933, jan./mar. 2010.

MORRIS, R. D.; HAM, T.; GRAY, S. J. The Value Relevance of Tranparency an Corporate Governance in Malaysia Before and After the Asian Financial Crisis.

Abacus - A Journal Accounting, Finance and Business Studies, Sidney, v. 47, n. 2, p. 205-233, 2011.

MOURA, G. D.; FRANZ, L.; CUNHA, P. R. Qualidade da informação contábil em empresas familiares: influência dos níveis diferenciados de governança da BM\&FBovespa, Tamanho e Independência do Conselho de Administração. In: SIMPÓSIO DE ADMINISTRAÇÃO DA PRODUÇÃO, LOGÍSTICA E OPERAÇÕES INTERNACIONAIS - SIMPOI, 16., São Paulo. Anais... São Paulo, 2013. Disponível em: < http://www.simpoi.fgvsp.br/arquivo/2013/artigos/ E2013_T00203_PCN84663.pdf>. Acesso em: 05 abr. 2014. 
MYERS, S. C.; MAJLUF, N. S. Corporate Financing and Investment Decisions when Firms have Information that Investors do not have. Journal of Finance Economics, p. 187-221, 1984.

O' GLOVE, T. L.; SOBEL, R. Quality Earnings: the investor's guide to how much money a companhy is really making. New York: The Free Press, 1987.

OLIVEIRA, K. P. S. et al. Governança Corporativa, Assimetria e Qualidade da Informação Contábil no Mercado Brasileiro de Capitais. In: CONGRESSO USP DE CONTROLADORIA E CONTABILIDADE, 14., 2014, São Paulo. Anais... São Paulo, 2013. Disponível em: < http://congressousp.fipecafi.org/web/ artigos142014/387.pdf>. Acesso em: 30 abr. 2014.

OLIVEIRA, M. C.; LINHARES, J. S. A implantação de controle interno adequado às exigências da Lei Sarbanes-Oxley em empresas brasileiras - Um estudo de caso. BASE - Revista de Administração e Contabilidade da Unisinos, Blumenau, v. 4, n. 2, p. 160-170, maio/ago. 2007.

RAUPP, F. M.; BEUREN, I. M. Metodologia Aplicável às Ciências Sociais. In: BEUREN, I. M. Como elaborar trabalhos monográficos em Contabilidade: teoria e prática. São Paulo: Atlas, 2006.

RONEN, J. Post-enron Reform: Financial Statement Insurance, and GAAP Re-Visited. In: DI PIETRA, R.; MCLEAY, S.; RONEN, J. Accounting and Regulation: New Ingihts on Governance, Markets and Institutions. New York: Springer, 2014.

SAITO, R.; SILVEIRA, A. D. Governança Corporativa: Custos de agência e Estrutura de Propriedade. RAE - Revista de Administração de Empresas, São Paulo, v. 48, n. 2, p. 79-86, abr.jun. 2008.

SANTANA, A. G. et al. Auditoria Independente e a Qualidade da Informação na Divulgação das Demonstrações Contábeis: Estudo Comparativo entre Empresas Brasileiras Auditadas pelas Big Four e Não Big Four. Revista de Contabilidade do Mestrado em Ciências Contábeis da UERJ, Rio de Janeiro, v. 19, n. 3, p. 70-87, set./dez. 2014.

SANTOS, A. C.; STAROSKY FILHO, L.; KLANN, R. C. Efeitos do processo de convergência às normas internacionais de contabilidade no value relevance das demonstrações contábeis de organizações brasileiras. Revista Contemporânea de Contabilidade, Florianópolis, v. 11, n. 22, p. 95-118, jan./abr. 2014.

SANTOS, M. A. C.; DIAS, L. N. S.; DANTAS, J. A. Teorias normativa e positiva da contabilidade. In: NIYAMA, J. K. Teoria Avançada da Contabilidade. São Paulo: Atlas, 2014. 
SHARPE, W.F. Capital assets prices: A theory of Market equilibrium under conditions of risk. Journal of Finance, v.19, n.3, p.425-442, 1964.

SIAGIAN, F.; SIREGAR, S. V.; RAHADIAN, Y. Corporate governance, reporting quality, and firm value: evidence from Indonesia. Journal of Accounting in Economy Emerging, v. 3, n. 1, p. 4-20, 2013.

SOUSA, C. B. et al. Valor de mercado e disclosure voluntário: estudo empírico em companhias listadas na BM\&FBOVESPA. Revista Ambiente Contábil, Natal, v. 6, n. 2, p. 94-115, jul./dez. 2014.

SUNDER, S. Teoria da Contabilidade e do Controle. São Paulo: Atlas, 2014. $261 \mathrm{p}$.

VERRECCHIA, R. E. Essays on disclosure. Journal of Accounting and Economics, n. 32, p. 97-180, 2001.

VERRECCHIA, R. E. Information Quality and Disclosure Discritionary. Journal of Accounting and Economics, North-Holland, v. 12, p. 365-380, 1990.

WATTS, R. L. Accounting Choice Theory and Market-Based Research In Accounting. British Accounting Review, n. 24, p. 235-267, 1992.

WATTS, R. L.; ZIMMERMAN, J. L. Positive accounting theory. Upper Saddle River: Prentice Hall, 1986.

WERDER, A. Corporate Governance and Stakeholder Opportunism. Organization Science, v. 22, n. 5, p. 1345-1358, 2014.

WOOLDRIDGE, J. M. Econometric analysis of cross section and data panel. 2. ed. Massachussets: Massachussets Institute of Technology, 2010.

YAMAMOTO, M. M.; SALOTTI, B. M. Informação contábil: estudos sobre a sua divulgação no mercado de capitais. São Paulo: Atlas, 2006. 


\section{Como citar este artigo:}

MARQUES, Vagner Antonio et al. Qualidade informacional e nível de $F$ transparência: um estudo entre empresas ganhadoras e não ganhadoras do troféu

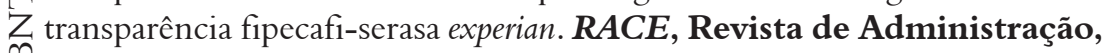
Contabilidade e Economia, Joaçaba: Ed. Unoesc, v. 14, n. 2, p. 769-796, maio/ ago. 2015. Disponível em: < http://editora.unoesc.edu.br/index.php/race>. Acesso em: dia/mês/ano.

MARQUES, V. A., SILVA, F. G. D. da, LOUZADA, L. C., AMARAL, H. F., \& SOUZA, A. A. de. (2015). Qualidade informacional e nível de transparência:

um estudo entre empresas ganhadoras e não ganhadoras do troféu transparência

$\varangle$ fipecafi-serasa experian. RACE, Revista de Administração, Contabilidade e Economia, 14(2), 769-796. Recuperado em dia/mês/ano, de http://editora.unoesc.edu.br/ index.php/race 